\title{
Ethnic differences in sedentary behaviour in 6-8-year-old children during school terms and school holidays: a mixed methods study
}

\author{
Liana C. Nagy ${ }^{1,2,3^{*}}$, Maria Horne ${ }^{2,4}$, Muhammad Faisal ${ }^{1,2}$, M. A. Mohammed ${ }^{1,2,5}$ and Sally E. Barber ${ }^{1,2}$
}

\begin{abstract}
Background: Sedentary behaviour (SB) in childhood is a major public health concern. Little is known about ethnic differences in SB during school and holiday weeks among White British (WB) and South Asian (SA) children, which this study aims to address through investigating inclinometer measured SB and exploring reasons for child engagement in SB.

Methods: A mixed methods study, comprising of a quantitative investigation with 160, 6-8 years old children and a qualitative study with a subsample of 18 children, six parents and eight teachers was undertaken. Children of WB and SA ethnicity in three schools were invited to wear inclinometers for seven school terms (summer/winter/ spring) and seven holidays (winter/spring) days during July 2016-May 2017. Total SB, SB accumulated in bouts $>30$ min and breaks in SB were explored using multivariate linear mixed effects models which adjusted for wear time, sex, deprivation, overweight status, season, term, weekday and school.

Nine focus groups and two interviews were carried out using the Theoretical Domains Framework to explore SB perceptions among parents, teachers and children. Data were analysed using the Framework Approach.

Results: 104/160 children provided 836 valid days of data. Children spent on average eight hours of SB/day during term time and holidays, equating to $60 \%$ of their awake time, and had on average 111 SB breaks /day. SA children had 25 fewer SB breaks/ day when compared to WB $(p<0.001)$. Perceived reasons for engagement in SB included: boredom, enjoyment of screen activities (by children), parenting practices, curriculum pressures (by teachers), the need to sit down and learn, and child's preference for screen activities (by parents).

Conclusions: Children spent $60 \%$ of their awake time being sedentary, regardless of ethnicity or school term. There were no significant ethnic differences for any of the SB outcomes except for breaks in SB. Interventions aimed at reducing SB should consider involving parents and teachers and should focus on increasing breaks in SB, especially for SA children, who are at a higher risk of cardio metabolic ill health.
\end{abstract}

Keywords: Sedentary behaviour, sitting, Physical activity, activPAL, Ethnicity

\footnotetext{
* Correspondence: Inagy@brookes.ac.uk

${ }^{1}$ University of Bradford, Faculty of Health Studies, Richmond Road, Bradford

BD7 1DP, England

${ }^{2}$ Bradford Institute for Health Research, Bradford Teaching Hospitals

Foundation Trust, Bradford BD9 6RJ, England

Full list of author information is available at the end of the article
}

(c) The Author(s). 2019 Open Access This article is distributed under the terms of the Creative Commons Attribution 4.0 International License (http://creativecommons.org/licenses/by/4.0/) which permits unrestricted use, distribution, and reproduction in any medium, provided you give appropriate credit to the original author(s) and the source, provide a link to the Creative Commons license, and indicate if changes were made. The Creative Commons Public Domain Dedication waiver (http://creativecommons.org/publicdomain/zero/1.0/) applies to the data made available in this article, unless otherwise stated. 


\section{Background}

The importance of investigating sedentary behaviour (SB) in children has been justified by the growing body of evidence linking high levels of SB to poor child development outcomes, lower academic achievement, and unfavourable cardio-metabolic risk factors in later life [1-4]. Nonetheless, inconsistencies in research findings linking SB to poor health outcomes, as well as inconsistencies in establishing the determinants of SB in children, have been noted in the literature $[5,6]$ and are related to the methodological quality of some studies as well as the complexity of identifying the direction and interplay between determinants of SB. Furthermore, less is known about ethnic differences in SB in child populations $[7,8]$ and to the best of our knowledge, no European studies have investigated SB during school holidays, which constitutes $20 \%$ of a calendar year. A recent systematic review [9] reported that children spend over half of their unstructured afterschool time in SB. Only one Japanese study has considered SB during school holidays and identified significantly higher accelerometer measured SB during school holidays compared to school term [10]. Within the existing literature, the term "level of SB", depicts the amount of SB within a particular time window (whole day, before school, after school etc) and this has been classified as high or low without specific thresholds to define high and low SB. The SB research using inclinometry has started to focus on how total SB was accumulated, whether from short uninterrupted periods or prolonged bouts (over $30 \mathrm{~min}$ ) and this is particularly important since longer bouts of SB have been found to be more damaging to cardiovascular health $[11,12]$. Furthermore, minority ethnic groups have been found to have higher levels of SB and lover levels of PA [13]; ethnic differences are also seen in the prevalence and risk of chronic conditions $[14,15]$. Specifically, evidence supports that, compared to White Europeans, SA have an increased risk of cardiovascular health and type-2 diabetes; for example the prevalence of diabetes is six time higher among SA groups [16, 17].

The aim of the study was to investigate the extent to which SB, measured via inclinometry, differed between White British (WB) and SA, 6-8-year-old children during school terms and school holidays and to explore perceived reasons for child engagement in SB.

Very few studies have explored reasons for engagement in SB and to our knowledge none have adopted a mixed method approach to ethnic differences in SB in primary school age children.

\section{Methods}

\section{Ethical approval}

Institutional approval from the University of Bradford Ethical Committee (E 536 06/06/2016) was granted for the study.

\section{Design}

We used a mixed methods approach [18] comprising of a cross-sectional study with quantitative data collection at five time points and a qualitative study consisting of interviews and focus groups with parents, children and teachers. First, quantitative data was used to determine ethnic differences in activPal (PAL Technologies Ltd., Glasgow, UK) measured SB. At the same time, qualitative, interviews and focus groups were undertaken to determine perceived reasons for engagement in SB.

\section{Recruitment and consent}

A total of 492 children, of WB and SA ethnicity, aged 6-8-year-old from three schools in West Yorkshire, UK were invited to participate in the study investigating SB, which commenced in July 2016 and ended in May 2017. Different groups of children were invited at three different time points: summer, winter and spring. Signed parental consent was gained first followed by child assent before any data collection.

\section{Procedures and measurements}

Quantitative data collection commenced with the summer term 2016, followed by winter term 2017, winter holiday 2017, spring holiday 2017 and spring term 2017 for one week of activPal wear for each data collection period. The device was placed on the anterior side of the right thigh, in a nitrile sleeve, wrapped and attached using hypo allergic medical dressing making the device waterproof, secured on the leg and allowing for $24 \mathrm{~h}$ protocol.

Measurements included height (wall mounted standiometer: Seca UK, Birmingham UK), weight and body composition (measured with Tanita scales TBF-300 MA, Tokio, Japan and Tanita scales BC-418 MA, Tokio, Japan). Body mass index (BMI) $\mathrm{z}$-scores were calculated for each participant using the British growth reference [19]. Weight categories (normal weight, overweight, obese) were derived from BMI percentiles using Freeman et al. recommendations [20].

Parents completed a demographics questionnaire, which included postcode details, child date of birth and child ethnicity. Parents were asked to complete sleep diaries with their children on a daily basis. The index of multiple deprivation decile (IMD) was generated from individual postcodes and collapsed in three levels of socioeconomic status (SES): low for IMD 1-2, medium for IMD 3-5 and high for IMD greater than 5 . The outcomes of interest were total SB, minutes, SB minutes in bouts $\geq 30 \mathrm{~min}$, number of bouts $\geq 30 \mathrm{~min}$, number of breaks in SB and perceived reasons for high levels of SB.

\section{Qualitative data procedures}

All parents whose children participated in the summer data collection and all teachers working with 6-8-year-old 
children in each school were invited to take part in the qualitative part. Consent was given at the time of focus group. Three boys and three girls with valid data were selected from each school and invited to participate in a focus group. The focus group and interview guides were developed using the Theoretical Domains Framework (TDF) to elicit components which need to be addressed in order to change behaviour [21].

The focus group schedules were refined through four separate pilot tests carried out with a WB 7-year-old boy, his parent, a SA parent and a WB primary school teacher working in a predominantly SA school. The pilot tests were not included in the analysis. Minor changes were made to the questions such as changing some wording for the children's focus group. For example, instead of sedentary behaviour, the term "sitting" was used. A list of questions used in the focus group can be found in Appendix 1.The focus groups and interviews were conducted in a manner consistent with recommendations made by Kruger and Casey [22].

All focus groups and interviews were carried out in English by LN, audio-recorded and transcribed verbatim.

\section{Quantitative data analysis}

ActivPal data were downloaded using the manufacturer's software (activPal3 ${ }^{\text {mo }}$ Professional v.7.2.32, PAL Technologies Ltd., Glasgow, UK) which generated three Microsoft Excel files (EventMarker, Events.csv and EventsXYZ.csv), one "datx" file, one "def" file and one "pal" file for each device. The "csv" EventsXYZ files which contain the raw data were processed in Stata 13 [23] and used an algorithm designed for a 24-h protocol [24] to remove non-wear. As a quality control measure, several processed files were statistically and visually examined individually for plausibility of sleep/non-wear classification [25]. As only $30 \%$ of children returned completed sleep diaries, none were used in order to reduce subjectivity. A day was considered valid if it had minimum of 10 and a maximum $18 \mathrm{~h}$ of valid wear time. For a child to have had their data included in the analyses they had to have had at least three valid week days and at least one valid weekend day during school term and/or school holidays.

Data were analysed using multivariate linear mixed effects mixed modelling, assuming no interaction effects. A total of 9 models were built: one model for each of the three outcome variables in three data sets (whole data set, term data set and holiday data set). The covariates used were: wear time, sex, SES, weight status, weekend, occasion (holiday/term), season and school; the covariate of interest was ethnicity. Age was not included in the model since the age variation was minimal. Child was entered as a random effect. Statistical significance was set at $<0.05$.

\section{Qualitative data analysis}

The transcripts were anonymised and pseudonyms used. Data were analysed using Framework approach [26] with the TDF, as the indexing scheme to explore SB perceptions from a child, parent and teacher point of view. $\mathrm{LN}$ coded all transcripts using NVIVO11 [27] to code and manage the data. Codes were then discussed with the research team and together developed the indexing scheme, which was used by the first author to chart data. Discrepancies were discussed between two authors and consensus was reached through discussion. Data was then lifted from the text and placed under the thematic analytical working framework (the charting stage) headings after which key characteristics were analysed subtracting meaning, developing associations and explanations within context.

\section{Results}

\section{Quantitative results}

Out of 160 children who had parental consent and participated in the study, 104 (Table 1) had valid data which generated 836 valid days of term and holiday days.

On average children were 7.51 years of age and the male/female ratio was close to one $(51 / 53=0.96)$. The ethnic composition of the sample was representative of the area [28], 58\% WB and $42 \%$ SA. There was a high percentage (42\%) of children from the lowest SES status (IMD1-2) and the majority of them were SA. The majority of children were of normal weight $(75 \%)$ and the percentage of overweight/obese was 25\% [29]. A higher percentage of SA children were obese $(22.73 \%)$ compared to WB (8.33). Across the whole data set (terms and holidays) children had an average of $814(\mathrm{SD}=41)$ minutes of valid wear. Sixty percent $(490 \mathrm{~min})$ of this was spent in SB and124 (SD =101) minutes $(24 \%)$ of the total SB was generated from long bouts $\geq 30 \mathrm{~min}$. On average children broke their SB $111(\mathrm{SD}=19)$ times per day which generated 111 bouts of $\mathrm{SB}$ and 2 were bouts $\geq 30 \mathrm{~min}$ (Table 2).

After adjusting for wear time (divided in tertiles), sex, deprivation, weight status, season, occasion (term/holiday),

Table 1 Demographics of the children with valid data

\begin{tabular}{llll}
\hline & $\begin{array}{l}\text { All children } \\
(n=104)\end{array}$ & $\begin{array}{l}\text { WB children } \\
(n=60)\end{array}$ & $\begin{array}{l}\text { SA children } \\
(n=44)\end{array}$ \\
\hline Age (years), mean(SD) & $7.51(0.52)$ & $7.48(0.50)$ & $7.50(0.54)$ \\
Male (\%) & $51(49.04)$ & $29(48.33)$ & $22(50.00)$ \\
Low SES (\%) & $44(42.31)$ & $9(15.00)$ & $35(79.55)$ \\
Medium SES (\%) & $45(43.27)$ & $36(60.00)$ & $9(20.45)$ \\
High SES (\%) & $15(14.42)$ & $15(25.00)$ & $0(0.00)$ \\
Normal weight (\%) & $78(75)$ & $46(76.67)$ & $32(72.73)$ \\
Overweight (\%) & $11(10.58)$ & $9(15)$ & $2(4.55)$ \\
Obese (\%) & $15(14.42)$ & $5(8.33)$ & $10(22.73)$ \\
zbmiuk (SD) & $0.32(1.20)$ & $0.30(1.03)$ & $0.34(1.40)$
\end{tabular}

zbmiuk - child bmi z scores based on the British growth reference (UK90) 
Table 2 Unadjusted averages for wear time and SB outcomes in three data sets

\begin{tabular}{|c|c|c|c|c|c|c|c|}
\hline & Valid days & $\begin{array}{l}\text { Wear time minutes } \\
\text { (mean, SD) }\end{array}$ & $\begin{array}{l}\text { Total SB minutes } \\
\text { (mean, SD) }\end{array}$ & $\begin{array}{l}\% \text { of total SB } \\
\text { out of wear time }\end{array}$ & $\begin{array}{l}\text { SB in bouts } \geq \\
30 \text { min (mean, SD) }\end{array}$ & $\begin{array}{l}\% \text { of short and long } \\
\text { bouts out of total SB }\end{array}$ & $\begin{array}{l}\text { Number of breaks } \\
\text { in SB (mean, SD) }\end{array}$ \\
\hline $\begin{array}{l}\text { Whole dataset } \\
N=104\end{array}$ & 836 & $\begin{array}{l}814 \\
(41)\end{array}$ & $\begin{array}{l}490 \\
(56)\end{array}$ & 60 & $\begin{array}{l}124 \\
(101)\end{array}$ & $\begin{array}{l}74 \\
26\end{array}$ & $\begin{array}{l}111 \\
(19)\end{array}$ \\
\hline $\begin{array}{l}\text { Term time } \\
N=85\end{array}$ & 519 & $\begin{array}{l}820 \\
(44)\end{array}$ & $\begin{array}{l}492 \\
(55)\end{array}$ & 60 & $\begin{array}{l}116 \\
(58)\end{array}$ & $\begin{array}{l}76 \\
24\end{array}$ & $\begin{array}{l}112 \\
(17)\end{array}$ \\
\hline $\begin{array}{l}\text { Holiday } \\
N=48\end{array}$ & 317 & $\begin{array}{l}804 \\
(42)\end{array}$ & $\begin{array}{l}488 \\
(71)\end{array}$ & 61 & $\begin{array}{l}136 \\
(59)\end{array}$ & $\begin{array}{l}71 \\
29\end{array}$ & $\begin{array}{l}110 \\
(22)\end{array}$ \\
\hline
\end{tabular}

weekday and school, no statistically significant $(p<0.005)$ differences were found between WB and SA children except in for one aspect of SB: SA children have 25 fewer breaks in $\mathrm{SB}$ compared to WB children $(p<0.01)$.

Other statistically significant differences relate to seasonality, SES and school as presented in Table 3 (Results from statistical models based on the whole data set).

The models for term time showed the same trend in ethnicity as for the whole data set model: no significant ethnic differences for any aspect of SB except for break in SB. SA children have 27 fewer SB breaks compared to WB children (Table 4).

The trend for fewer SB breaks for SA children is observed in the holiday's model (Table 5) with 19 fewer breaks $(p<0.05)$. Except breaks in SB, there are no other ethnicity differences for any SB outcomes.

\section{Qualitative results}

Eighteen children, six parents and eight teachers participated in eight focus groups and 2 interviews. All meetings were intended to be focus groups but due to participant availability, two of them became interviews. Focus groups characteristics are provided in Table 6.

Although the whole qualitative exploration was in depth and explored numerous aspects of SB, this article will report specifically on the reasons for child engagement in SB.

Child, parent and teachers' perceived reasons were mapped onto several TDF components: emotion, social influences, and professional role. Teachers and children perceived enjoyment and child's preference for screen viewing activities as a reason for child engagement in $\mathrm{SB}$, whilst some parents described screen viewing activities as an addiction:

"I know [child's name], if I wouldn't say he can't have it ...he would be on it $24 \mathrm{hrs}$, take it to bed and sleep with it." (WB parent, School C).

All parents felt that learning requires sitting and one cannot be focused if "on the move".

"They are somewhat more focused if they are sat in one place so they can focus on what they are doing instead of just walking around." (WB Parent, School A).
Intra- personal reasons for $\mathrm{SB}$, such as laziness, boredom and enjoyment to sit for screen viewing activities were aspects identified by boys and girls as reasons for engagement in SB:

"They are not active, they don't like jumping and running, they just like sitting on the sofa and watching $T V$, they might have a habit of sitting." (SA Girl, School B).

"And if you lazy you keep on playing with your phone" (SA Boy, School B).

Children reported numerous circumstances when they were told to sit which included classroom time, visiting grandparents, going to church or mosque, eating and or watching TV. Spending time at the mosques on a regular basis for SA children appeared to be the only ethnic difference for reason to engaging in SB.

Teachers felt that the child's level of SB was a result of the family's lifestyle, for example if the child had active parents, the child would be less sedentary. Teachers in predominantly SA schools perceived SA parents as overprotecting of their children and not seeing the importance of PA.

"There are lots of children who would stay inside and there are an awful lot of parents who would say, aw so and so has got a cold today he needs to stay inside, you know he is feeling tired. I don't think the parents see the importance of being outside in fresh air, burning energy and things like that" (School B, Teacher).

Teachers agreed that the demands and focus on academic outcomes have become heavier in the recent years, which they felt contributed to sitting down for longer periods to complete academic work:

"Demand. Curriculum got more difficult, the government are tracking more, they have more tests, tests are harder so what you have to do now in the classroom is much more difficult and there is other things ...I think that's why." (Teacher in School C). 
Table 3 Model coefficients for three SB outcomes based on the whole data set

\begin{tabular}{|c|c|c|c|}
\hline Covariate & $\begin{array}{c}\text { Total SB } \\
\text { Min to Max } \\
\text { P value }\end{array}$ & $\begin{array}{c}S B>30 \\
\text { Min to Max } \\
P \text { value }\end{array}$ & $\begin{array}{l}\text { SB breaks } \\
\text { Min to Max } \\
\text { P value }\end{array}$ \\
\hline South Asian & $\begin{array}{c}8.85 \\
(-30.23 \text { to } 47.92) \\
p=0.657\end{array}$ & $\begin{array}{c}7.98 \\
(-30.2 \text { to } 46.16) \\
p=0.682\end{array}$ & $\begin{array}{c}-24.85 \\
(-36.65 \text { to }-13.05) \\
p<0.001\end{array}$ \\
\hline Male & $\begin{array}{c}-1.6 \\
(-21.71 \text { to } 18.5) \\
p=0.876\end{array}$ & $\begin{array}{c}6.26 \\
(-13.48 \text { to } 26.01) \\
p=0.534\end{array}$ & $\begin{array}{c}-5.07 \\
(-11.15 \text { to } 1) \\
p=0.102\end{array}$ \\
\hline $\begin{array}{l}\text { Overweigh } \\
\text { (reference } \\
\text { normal weight }\end{array}$ & $\begin{array}{c}-27.12 \\
(-61.77 \text { to } 7.53) \\
p=0.125\end{array}$ & $\begin{array}{c}-21.95 \\
(-56.22 \text { to } 12.31) \\
p=0.209\end{array}$ & $\begin{array}{c}0.26 \\
(-10.21 \text { to } 10.74) \\
p=0.961\end{array}$ \\
\hline $\begin{array}{c}\text { Obese } \\
\text { (reference } \\
\text { normal weight) }\end{array}$ & $\begin{array}{c}-3.19 \\
(-32.53 \text { to } 26.15) \\
p=0.831\end{array}$ & $\begin{array}{c}-12.29 \\
(-41.18 \text { to } 16.6) \\
p=0.405\end{array}$ & $\begin{array}{c}-0.22 \\
(-9.08 \text { to } 8.65) \\
p=0.961\end{array}$ \\
\hline $\begin{array}{l}\text { Medium SES } \\
\text { (reference low } \\
\text { SES) }\end{array}$ & $\begin{array}{c}-9.58 \\
(-38.1 \text { to } 18.94) \\
p=0.51\end{array}$ & $\begin{array}{c}-5.46 \\
(-33.41 \text { to } 22.48) \\
p=0.702\end{array}$ & $\begin{array}{c}-9.76 \\
(-18.37 \text { to }-1.14) \\
p=0.026\end{array}$ \\
\hline $\begin{array}{c}\text { High SES } \\
\text { (reference low } \\
\text { SES) }\end{array}$ & $\begin{array}{c}-5.66 \\
(-47.41 \text { to } 36.1) \\
p=0.791\end{array}$ & $\begin{array}{c}6.62 \\
(-34.4 \text { to } 47.65) \\
p=0.752\end{array}$ & $\begin{array}{c}-10.72 \\
(-23.34 \text { to } 1.89) \\
p=0.096\end{array}$ \\
\hline Term & $\begin{array}{c}-7.73 \\
(-21.72 \text { to } 6.26) \\
p=0.279\end{array}$ & $\begin{array}{c}-30.73 \\
(-46.59 \text { to }-14.87) \\
p<0.001\end{array}$ & $\begin{array}{c}1.81 \\
(-2.47 \text { to } 6.09) \\
p=0.408\end{array}$ \\
\hline Weekend & $\begin{array}{c}10.57 \\
(-0.78 \text { to } 21.91) \\
p=0.068\end{array}$ & $\begin{array}{c}39.68 \\
(26.4 \text { to } 52.96) \\
p<0.001\end{array}$ & $\begin{array}{c}-2.09 \\
(-5.57 \text { to } 1.39) \\
p=0.24\end{array}$ \\
\hline Winter & $\begin{array}{c}36.65 \\
(13.11 \text { to } 60.2) \\
p=0.002\end{array}$ & $\begin{array}{c}-2.09 \\
(-25.76 \text { to } 21.59) \\
p=0.863\end{array}$ & $\begin{array}{c}-2.95 \\
(-10.07 \text { to } 4.18) \\
p=0.418\end{array}$ \\
\hline Spring & $\begin{array}{c}-3.39 \\
(-34.33 \text { to } 27.55) \\
p=0.83\end{array}$ & $\begin{array}{c}-16.13 \\
(-47.13 \text { to } 14.87) \\
p=0.308\end{array}$ & $\begin{array}{c}3.91 \\
(-5.45 \text { to } 13.27) \\
p=0.413\end{array}$ \\
\hline School B & $\begin{array}{c}-0.22 \\
(-50.42 \text { to } 49.98) \\
p=0.993\end{array}$ & $\begin{array}{c}-3.77 \\
(-52.67 \text { to } 45.14) \\
p=0.88\end{array}$ & $\begin{array}{c}18.39 \\
(3.24 \text { to } 33.55) \\
p=0.017\end{array}$ \\
\hline School C & $\begin{array}{c}-8.98 \\
(-39.46 \text { to } 21.5) \\
p=0.564\end{array}$ & $\begin{array}{c}-22.81 \\
(-52.7 \text { to } 7.09) \\
p=0.135\end{array}$ & $\begin{array}{c}14.09 \\
(4.88 \text { to } 23.3) \\
p=0.003\end{array}$ \\
\hline
\end{tabular}

It appears that adults have a more significant role than children in contributing to children's engagement or disengagement with SB since children are told by adults when to sit and are guided towards activities that required sitting or not. They are therefore likely to also provide part of the solution and the means to reducing child SB. 
Table 4 Model coefficients for three SB outcomes based on school terms data

\begin{tabular}{|c|c|c|c|}
\hline Covariate & $\begin{array}{c}\text { Total SB in } \\
\text { minutes } \\
\text { Mean (min to max) } \\
\text { p-value }\end{array}$ & $\begin{array}{l}\text { SB from bouts } \geq 30 \\
\text { min } \\
\text { Mean (min to max) p- } \\
\text { value }\end{array}$ & $\begin{array}{l}\text { Number of breaks in SB } \\
\text { Mean (min to max), p- } \\
\text { value }\end{array}$ \\
\hline South Asian & $\begin{array}{c}-6.67 \\
(-48.4 \text { to } 35.07) \\
p=0.754\end{array}$ & $\begin{array}{c}-5.14 \\
(-56.9 \text { to } 46.62) \\
p=0.846\end{array}$ & $\begin{array}{c}-26.92 \\
(-40.67 \text { to }-13.16) \\
p<0.001\end{array}$ \\
\hline Sex (Male) & $\begin{array}{c}0.77 \\
(-17.78 \text { to } 19.32) \\
p=0.935\end{array}$ & $\begin{array}{c}2.36 \\
(-20.66 \text { to } 25.37) \\
p=0.841\end{array}$ & $\begin{array}{c}-2.77 \\
(-8.89 \text { to } 3.34) \\
p=0.374\end{array}$ \\
\hline $\begin{array}{l}\text { Overweight } \\
\text { (reference } \\
\text { normal } \\
\text { weight) }\end{array}$ & $\begin{array}{c}-4.17 \\
(-39.36 \text { to } 31.02) \\
p=0.816\end{array}$ & $\begin{array}{c}-5.51 \\
(-49.02 \text { to } 38) \\
p=0.804\end{array}$ & $\begin{array}{c}-7.36 \\
(-18.91 \text { to } 4.19) \\
p=0.211\end{array}$ \\
\hline Obese & $\begin{array}{c}12.56 \\
(-15.87 \text { to } 40.98) \\
p=0.387\end{array}$ & $\begin{array}{c}-2.13 \\
(-37.38 \text { to } 33.12) \\
p=0.906\end{array}$ & $\begin{array}{c}1.74 \\
(-7.63 \text { to } 11.1) \\
p=0.716\end{array}$ \\
\hline Medium SES & $\begin{array}{c}-13.87 \\
(-41.78 \text { to } 14.04) \\
p=0.33\end{array}$ & $\begin{array}{c}-8.1 \\
(-42.71 \text { to } 26.52) \\
p=0.647\end{array}$ & $\begin{array}{c}-6.71 \\
(-15.91 \text { to } 2.49) \\
p=0.153\end{array}$ \\
\hline High SES & $\begin{array}{c}-18.25 \\
(-57.29 \text { to } 20.78) \\
p=0.359\end{array}$ & $\begin{array}{c}4.89 \\
(-43.52 \text { to } 53.31) \\
p=0.843\end{array}$ & $\begin{array}{c}-9.51 \\
(-22.37 \text { to } 3.36) \\
p=0.147\end{array}$ \\
\hline weekend & $\begin{array}{c}13.02 \\
(-1.34 \text { to } 27.38) \\
p=0.076\end{array}$ & $\begin{array}{c}50.56 \\
(33.97 \text { to } 67.15) \\
p<0.001\end{array}$ & $\begin{array}{c}-1.71 \\
(-5.98 \text { to } 2.57) \\
p=0.433\end{array}$ \\
\hline $\begin{array}{l}\text { Winter } \\
\text { (reference } \\
\text { Summer) }\end{array}$ & $\begin{array}{c}41.49 \\
(21.75 \text { to } 61.24) \\
p<0.001\end{array}$ & $\begin{array}{c}-0.67 \\
(-25.13 \text { to } 23.79) \\
p=0.957\end{array}$ & $\begin{array}{c}-5.46 \\
(-11.96 \text { to } 1.03) \\
p=0.099\end{array}$ \\
\hline Spring & $\begin{array}{c}7.86 \\
(-22.76 \text { to } 38.49) \\
p=0.615\end{array}$ & $\begin{array}{c}-5.08 \\
(-43.02 \text { to } 32.87) \\
p=0.793\end{array}$ & $\begin{array}{c}1.02 \\
(-9.06 \text { to } 11.1) \\
p=0.843\end{array}$ \\
\hline School B & $\begin{array}{c}11.42 \\
(-37.16 \text { to } 60) \\
p=0.645\end{array}$ & $\begin{array}{c}18.68 \\
(-41.61 \text { to } 78.97) \\
p=0.544\end{array}$ & $\begin{array}{c}18.88 \\
(2.86 \text { to } 34.91) \\
p=0.021\end{array}$ \\
\hline School C & $\begin{array}{c}-4.92 \\
(-32.46 \text { to } 22.61) \\
p=0.726\end{array}$ & $\begin{array}{c}-22.44 \\
(-56.59 \text { to } 11.71) \\
p=0.198\end{array}$ & $\begin{array}{c}19.3 \\
(10.23 \text { to } 28.38) \\
p<0.001\end{array}$ \\
\hline
\end{tabular}

\section{Discussion}

The study found that WB and SA children spent $60 \%$ of their awake time in SB during term or holiday. Out of the total SB, $25 \%$ in bouts $\geq 30 \mathrm{~min}$. There were no significant differences between WB and SA children in SB except for breaks in SB. SA children had 25 fewer breaks compared to WB children. Among the perceived reasons for engagement in SB were: enjoyment of screen viewing, boredom, laziness, parenting, curriculum demands and the need to sit for academic learning.

This study highlighted the need for the overall reduction of SB regardless of ethnicity. Sitting has been compared to smoking in the recent literature $[30,31]$ because of its effects on health, and if this is the case, more needs to be 
Table 5 Model coefficients for three SB outcomes based on holidays data

\begin{tabular}{|c|c|c|c|}
\hline Covariate & $\begin{array}{l}\text { Total SB in minutes } \\
\text { Mean (min to max) } \\
\text { p-value }\end{array}$ & $\begin{array}{l}\text { SB from bouts } \geq 30 \text { min } \\
\text { Mean (min to max) } p- \\
\text { value }\end{array}$ & $\begin{array}{l}\text { Number of breaks in SB } \\
\text { Mean (min to max) p- } \\
\text { value }\end{array}$ \\
\hline South Asian & $\begin{array}{c}25.26 \\
(-29.74 \text { to } 80.25) \\
p=0.368\end{array}$ & $\begin{array}{c}18.93 \\
(-32.17 \text { to } 70.04) \\
p=0.468\end{array}$ & $\begin{array}{c}-19.37 \\
(-36.36 \text { to }-2.38) \\
p=0.025\end{array}$ \\
\hline Sex (Male) & $\begin{array}{c}6.8 \\
(-28.98 \text { to } 42.59) \\
p=0.709\end{array}$ & $\begin{array}{c}12.04 \\
(-21.29 \text { to } 45.38) \\
p=0.479\end{array}$ & $\begin{array}{c}-1.25 \\
(-12.31 \text { to } 9.8) \\
p=0.824\end{array}$ \\
\hline Overweight & $\begin{array}{c}-40.2 \\
(-97.84 \text { to } 17.43) \\
p=0.172\end{array}$ & $\begin{array}{c}-33.63 \\
(-87.22 \text { to } 19.97) \\
p=0.219\end{array}$ & $\begin{array}{c}6.08 \\
(-11.73 \text { to } 23.89) \\
p=0.503\end{array}$ \\
\hline Obese & $\begin{array}{c}-17.4 \\
(-67.85 \text { to } 33.05) \\
p=0.499\end{array}$ & $\begin{array}{c}-12.69 \\
(-59.83 \text { to } 34.45) \\
p=0.598\end{array}$ & $\begin{array}{c}-12.79 \\
(-28.37 \text { to } 2.8) \\
p=0.108\end{array}$ \\
\hline Medium SES & $\begin{array}{c}7.49 \\
(-36.85 \text { to } 51.83) \\
p=0.741\end{array}$ & $\begin{array}{c}6.57 \\
(-34.64 \text { to } 47.79) \\
p=0.755\end{array}$ & $\begin{array}{c}-16.26 \\
(-29.96 \text { to }-2.56) \\
p=0.02\end{array}$ \\
\hline High SES & $\begin{array}{c}26.25 \\
(-47.73 \text { to } 100.23) \\
p=0.487\end{array}$ & $\begin{array}{c}21.65 \\
(-47.17 \text { to } 90.47) \\
p=0.538\end{array}$ & $\begin{array}{c}-9.5 \\
(-32.36 \text { to } 13.35) \\
p=0.415\end{array}$ \\
\hline Weekend & $\begin{array}{c}8.83 \\
(-9.19 \text { to } 26.85) \\
p=0.337\end{array}$ & $\begin{array}{c}21.24 \\
(0.8 \text { to } 41.67) \\
p=0.042\end{array}$ & $\begin{array}{c}-3.08 \\
(-8.67 \text { to } 2.5) \\
p=0.28\end{array}$ \\
\hline $\begin{array}{l}\text { Spring } \\
\text { (reference } \\
\text { winter) }\end{array}$ & $\begin{array}{c}-37.2 \\
(-74.85 \text { to } 0.45) \\
p=0.053\end{array}$ & $\begin{array}{c}-18.41 \\
(-53.61 \text { to } 16.8) \\
p=0.305\end{array}$ & $\begin{array}{c}3.89 \\
(-7.75 \text { to } 15.52) \\
p=0.512\end{array}$ \\
\hline $\begin{array}{l}\text { School B } \\
\text { (reference } \\
\text { School A) }\end{array}$ & $\begin{array}{c}10.33 \\
(-68.7 \text { to } 89.36) \\
p=0.798\end{array}$ & $\begin{array}{c}-19.9 \\
(-93.23 \text { to } 53.44) \\
p=0.595\end{array}$ & $\begin{array}{c}14.17 \\
(-10.24 \text { to } 38.59) \\
p=0.255\end{array}$ \\
\hline School C & $\begin{array}{c}2.76 \\
(-51.92 \text { to } 57.44) \\
p=0.921\end{array}$ & $\begin{array}{c}-14.48 \\
(-65.26 \text { to } 36.3) \\
p=0.576\end{array}$ & $\begin{array}{c}2.41 \\
(-14.49 \text { to } 19.3) \\
p=0.78\end{array}$ \\
\hline
\end{tabular}

done to reduce it. The strength this study lies in its mixed methods design, inclusion of school holiday days in analyses and the focus on ethnic differences. The majority of studies evaluating SB are quantitative [9, 32-34] and very few are qualitative [35-37]. Fewer even have a mixed method design that allows for contextual data to explain some of the quantitative findings [38]. No European studies have yet considered SB during school holidays in any age group and within the field of physical activity and SB, studies that look at ethnic differences in primary school age children are only emerging [39].

The present study addressed the question of ethnicity in relation to $\mathrm{SB}$, giving a macro view of the whole day.
Specific evaluations of SB within time periods in the day that are relevant to primary school aged children might offer more insight and allow the identification of critical time periods when SB interventions are mostly needed.

A limitation of this study is the use an algorithm that was validated in adults to remove non-wear. To date there isn't a validated method for activPal data in child populations and most studies do no report how the non-wear time was addressed or use the accelerometry rule of 0 counts exclusion [40-42]. Non-wear time needs to be addressed when processing activPal data and further research should consider developing validated methods in child populations. To increase accuracy of 
Table 6 Focus groups and interviews participants' characteristics

\begin{tabular}{|c|c|c|c|c|c|}
\hline $\begin{array}{l}\text { Focus groups(FG) and } \\
\text { interviews }(n=10)\end{array}$ & $\begin{array}{l}\text { School } \\
(n=3)\end{array}$ & $\begin{array}{l}\text { School Index of Multiple } \\
\text { Deprivation decile }\end{array}$ & $\begin{array}{l}\text { Participants } \\
(n=32)\end{array}$ & $\begin{array}{l}\text { FG and interview Index } \\
\text { of Multiple Deprivation } \\
\text { decile }\end{array}$ & $\begin{array}{l}\text { Participants' } \\
\text { ethnicity }\end{array}$ \\
\hline FG1 & A & 4 & $\begin{array}{l}\text { Children } \\
\mathrm{n}=6\end{array}$ & $4,4,6,6,8,8$ & WB \\
\hline Interview 1 & A & 4 & $\begin{array}{l}\text { Parents } \\
\mathrm{n}=1\end{array}$ & 8 & WB \\
\hline FG2 & A & 4 & $\begin{array}{l}\text { Teachers } \\
n=3\end{array}$ & $\mathrm{n} / \mathrm{a}$ & WB \\
\hline FG3 & B & 1 & $\begin{array}{l}\text { Children } \\
n=6\end{array}$ & $1,1,1,1,3,3$ & SA \\
\hline FG4 & B & 1 & $\begin{array}{l}\text { Parents } \\
\mathrm{n}=2\end{array}$ & 3,1 & SA \\
\hline FG5 & B & 1 & $\begin{array}{l}\text { Teachers } \\
n=2\end{array}$ & $\mathrm{n} / \mathrm{a}$ & WB \\
\hline Interview 2 & B & 1 & $\begin{array}{l}\text { Teachers } \\
\mathrm{n}=1\end{array}$ & $\mathrm{n} / \mathrm{a}$ & WB \\
\hline FG6 & $C$ & 2 & $\begin{array}{l}\text { Children } \\
n=6\end{array}$ & $2,2,4,4,5,5$ & WB and SA \\
\hline FG7 & $C$ & 2 & $\begin{array}{l}\text { Parents } \\
\mathrm{n}=3\end{array}$ & $2,5,5$ & WB \\
\hline FG8 & C & 2 & $\begin{array}{l}\text { Teachers } \\
\mathrm{n}=2\end{array}$ & $\mathrm{n} / \mathrm{a}$ & WB \\
\hline
\end{tabular}

the results several files were visually inspected for quality control and manually processed, however further research needs to clarify how short periods of non-wear should be dealt with [25].

The sample of children who had valid data is modest $(104 / 160)$ and this was due to device availability and participant compliance with wearing the device. Non- compliance with device wear was also due to low tolerance for wearing the device for some children. Some children $(n=33)$ had a rash after several days of wearing the device, which was reported to the manufacturer. No other studies have reported on this issue but further research should consider developing alternative ways to device attachment.

The cross-sectional design of the study comes with its limitations and no conclusions could be made about the determinants of SB in children of SA or WB ethnicity. To date no longitudinal study has reported results using the activPal and this is likely to do with the age of the device as the first ever study using activPal was published in 2007 [43].

All children in this study spent eight hours of their awake time in SB regardless of ethnicity which is comparable with office workers SB [44]. The qualitative data gave some insight into underlying reasons for engagement in SB but further exploration is required. Nonetheless, unpublished questionnaire data from the Born in Bradford cohort study (completed 2016/2017) with 2356 children of SA ethnicity who completed the religion section might provide possible clues. Of all the SA children who completed the religion questions, $96 \%$ identified themselves as being Muslim, 91\% said that they attended Mosque/Madrassa and 85\% said they attended Mosque/ Madrassa on some or most days of the week $(71 \%$, most days of the week). Children spend $1-2 \mathrm{~h}$ daily at madrasa and it is expected they are mostly seated as this is a religion and language learning environment. The way in which prayers are done requires changes in posture but the proportion of $\mathrm{SB}$ accumulated during the week is unclear as no device recorded data on child SB in mosques is available.

This study did not find any significant SB differences between term and school holiday, which is contrary to previous studies $[45,46]$ evidencing increased SB during unstructured periods of time (after school hours or weekend). The reasons for this are unclear and it warrants further research. It was also anticipated that there would be significant ethnic differences in the total SB based on results from studies evaluating ethnic differences in SB in child populations in Bradford [8, 47, 48]. However, this was not the case for our study. SB increases with age and a possible explanation for the lack of ethnic differences is the age group of the children evaluated. Inclinometer recorded data from older children (9-10 years old) in Bradford highlighted significant ethnic differences in the total SB [47]. Twenty-five percent of children in our study were overweight and obese which is similar to data published in the UK [49]. The recent predictions by World Health Organization (WHO) on rising child overweight and obesity to $40 \%$ by 2030 , if no action is taken, are 
relevant for both developed and developing countries. Part of the WHO strategy for reducing overweight and obesity is to reduce $\mathrm{SB}$ [50].

A recent systematic review reported a rise in $\mathrm{SB}$ as children transition to secondary school [32]. Given the findings of our study, this is concerning if the already high levels of $\mathrm{SB}$ are expected to rise. The results on total SB in our study are comparable with the results of the systematic review for children already at transition [32], but the studies included in the review were published between 1999 and 2015 and it is likely that due to increasing use of screen devices, the total SB may also be increasing.

A standing issue relates to guidelines and practices that contribute to increasing levels of SB. Whilst there are recommended guidelines for levels of MVPA for children there are no such guidelines for SB. In the 2016 Report Card on Physical Activity for Children and Youth [51], the results on SB has received an incomplete grade due to lack of guidelines. Our findings highlight an urgent need to address SB in school children who are as sedentary as office workers. As schools have often been identified to be optimal environments for physical activity interventions, school policies could consider adopting a benchmark for SB during school time. As adults are likely to be more significant contributors to child engagement in sedentary behaviour, interventions aimed at reducing SB should consider including parents and teachers [52].

\section{Conclusions}

Our study has highlighted high levels of SB regardless of ethnicity and showed no significant ethnic differences in SB except for breaks in SB. Since breaks in SB are desirable for cardiovascular health, interventions aimed at reducing $\mathrm{SB}$ should also consider increasing breaks in $\mathrm{SB}$, especially for SA children who are at a higher risk of cardio metabolic ill health in adulthood.

\section{Abbreviations}

FG: Focus group; IMD: Index of Multiple Deprivation; MVPA: Moderate to vigorous physical activity; PA: Physical activity; SA: South Asian; SB: Sedentary behaviour; SES: Socioeconomic status; TDF: Theoretical Domains Framework; WB: White British; WHO: World Health Organisation

\section{Acknowledgements}

We thank all the participants and their families for their time and ongoing participation in the study. We also thank all the researchers involved in data collection.

\section{Funding}

This research was funded by the NIHR Collaboration for Leadership in Applied Health Research and Care Yorkshire and Humber (NIHR CLAHRC YH). www.clahrc-yh.nihr.ac.uk. The views and opinions expressed are those of the authors, and not necessarily those of the NHS, the NIHR or the Department of Health.

Availability of data and materials

The data are not publically available due to confidentiality restrictions.

\section{Authors' contributions}

LCN, SEB, MH defined the research question. MAM, MF and LCN wrote the statistical analysis plan and conducted the statistical analysis. LCN and $\mathrm{MH}$ the analysed the qualitative. LCN drafted the manuscript. LN, SEB, MH and MAM contributed to the interpretation of the results. All authors contributed to critical revisions and approved the final draft.

\section{Ethics approval and consent to participate}

Ethics approval was received from the University of Bradford Ethics Committee (E536 on 06/06/2016). Written consent was gained from parents and teachers. Signed child assent was gained from children whose parents consented for their participation.

\section{Consent for publication}

Not applicable.

\section{Competing interests}

None.

\section{Publisher's Note}

Springer Nature remains neutral with regard to jurisdictional claims in published maps and institutional affiliations.

\section{Author details}

'University of Bradford, Faculty of Health Studies, Richmond Road, Bradford BD7 1DP, England. ${ }^{2}$ Bradford Institute for Health Research, Bradford Teaching Hospitals Foundation Trust, Bradford BD9 6RJ, England. ${ }^{3}$ Oxford Brookes University, Faculty of Health and Life Sciences, Jack Straw's Lane, Oxford OX3 OFL, UK. ${ }^{4}$ University of Leeds, School of Healthcare, Leeds LS2 9JT, England.

${ }^{5}$ Yorkshire \& Humberside Academic Health Sciences Network, Wakefield, UK.

Received: 31 May 2018 Accepted: 18 January 2019

Published online: 04 February 2019

References

1. Busto-Zapico R, Amigo-Vázquez I, Peña-Suárez E, Fernández-Rodríguez C. Relationships between sleeping habits, sedentary leisure activities and childhood overweight and obesity. Psychol health med. 2014;(October 2014): 37-41. Available from: http://www.ncbi.nlm.nih.gov/pubmed/24410653.

2. Carson V, Clark M, Berry T, Holt NL, Latimer-Cheung AE. A qualitative examination of the perceptions of parents on the Canadian sedentary behaviour guidelines for the early years. Int J Behav Nutr Phys Act. 2014; 11(1):65.

3. Chinapaw MJ, Proper Kl, Brug J, Mechelen W, Singh AS. Relationship between young peoples' sedentary behaviour and biomedical health indicators: a systematic review of prospective studies. Obes rev. 2011;12 Available from: https://doi.org/10.1111/j.1467-789X.2011.00865.x.

4. Poitras VJ, Gray CE, Borghese MM, Carson V, Chaput J, Janssen I, et al. Systematic review of the relationships between objectively measured physical activity and health indicators in school-aged children and youth. Appl Physiol Nutr Metab. 2016;41(6):s197-s239.

5. Uijtdewilligen L, Nauta J, Singh AS, van Mechelen W, Twisk JWR, van der Horst K, et al. Determinants of physical activity and sedentary behaviour in young people: a review and quality synthesis of prospective studies. $\mathrm{Br} \mathrm{J}$ Sports Med. 2011:45(11):896-905.

6. Stierlin AS, De Lepeleere S, Cardon G, Dargent-Molina P, Hoffmann B, Murphy $\mathrm{MH}$, et al. A systematic review of determinants of sedentary behaviour in youth: a DEDIPAC-study. Int J Behav Nutr Phys Act. 2015 Oct; 12(1):133. Available from: https://doi.org/10.1186/s12966-015-0291-4.

7. Sisson SB, Church TS, Martin CK, Smith SR, Bouchard C, Earnest CP, et al. Profiles of Sedentary Behavior in Children and Adolescents: The U.S. National Health and Nutrition Examination Survey, 2001-2006. Int J Pediatr Obes. 2010;4(4):353-9.

8. Barber SE, Kelly B, Collings PJ, Nagy L, Bywater T, Wright J. Prevalence, trajectories, and determinants of television viewing time in an ethnically diverse sample of young children from the UK. Int J Behav Nutr Phys Act. 2017;14(1):88-99.

9. Arundell L, Fletcher E, Salmon J, Veitch J, Hinkley T. A systematic review of the prevalence of sedentary behavior during the after-school period among children aged 5-18 years. Int J Behav Nutr Phys Act. International Journal of Behavioral Nutrition and Physical Activity; 2016 Aug:13(1):93. Available from: http://ijbnpa.biomedcentral.com/articles/10.1186/s12966-016-0419-1 
10. Tanaka C, Reilly JJ, Tanaka M, Tanaka S. Seasonal changes in objectively measured sedentary behavior and physical activity in Japanese primary school children. BMC Public Health. London: BioMed Central; 2016;16(1):969. Available from: http://www.ncbi.n/m.nih.gov/pmc/articles/PMC5020446/

11. Edwardson CL, Henson J, Bodicoat DH, Bakrania K, Khunti K, Davies MJ, et al. Associations of reallocating sitting time into standing or stepping with glucose, insulin and insulin sensitivity: a cross-sectional analysis of adults at risk of type 2 diabetes. BMJ Open. 2017;7(1) Available from: http://bmjopen. bmj.com/content/7/1/e014267.abstract.

12. Dunstan KBA, Larsen R, Healy GN, Cerin E, Hamilton MT, et al. Breaking Up Prolonged Sitting Reduces Postprandial Glucose and Insulin Responses. Diabetes Care. 2012;35(5):976 LP-983 Available from: http://care. diabetesjournals.org/content/35/5/976.abstract.

13. Langøien LJ, Terragni L, Rugseth G, Nicolaou M, Holdsworth M, Stronks K, et al. Systematic mapping review of the factors influencing physical activity and sedentary behaviour in ethnic minority groups in Europe: a DEDIPAC study. Int J Behav Nutr Phys Act. 2017;14(1):99 Available from: https://doi. org/10.1186/s12966-017-0554-3.

14. Bhopal R, Unwin N, White M, Yallop J, Walker L, Alberti KGMM, et al. Heterogeneity of coronary heart disease risk factors in Indian, Pakistani, Bangladeshi, and European origin populations: cross sectional study. BMJ. 1999:319(7204):215 LP-220.

15. Santos VA, PL S, AN T, Milan G, Abha K, KA V, et al. Atherosclerotic Cardiovascular Disease in South Asians in the United States: Epidemiology, Risk Factors, and Treatments: A Scientific Statement From the American Heart Association. Circulation. American Heart Association. 2018;138(1):e1-34.

16. Stuckey HL, Dellasega C, Graber NJ, Mauger DT, Lendel I, Gabbay RA. Diabetes UK and South Asian Health Foundation recommendations on diabetes research priorities for British South Asians. Diabetes. 2010:366-74.

17. Gholap N, Davies M, Patel K, Sattar N, Khunti K. Type 2 diabetes and cardiovascular disease in south Asians. Prim care diabetes [internet]. Elsevier; 2011;5(1):45-56. Available from: https://doi.org/10.1016/j.pcd.2010.08.002

18. Teddlie C, Tashakkori A. Foundations of mixed methods research: integrating quantitative and qualitative approaches in the social and behavioral sciences [internet]. Book 2009. 387 p. Available from: http:// books.google.com/books?hl=en\&lr=\&id=XvMAYYvS1rEC\&pgis=1

19. Cole TJ, Freeman JV, Preece MA. Body mass index reference curves for the UK, 1990. Arch Dis ChildhoodArch Dis Child. 1995;73(73):25-9.

20. Freeman V, Cole TJ, Chinn S, Jones PRM, White EM, Preece MA. Cross sectional stature and weight reference curves for the UK, 1990. 1995;17-24.

21. Cane J, O'Connor D, Michie S. Validation of the theoretical domains framework for use in behaviour change and implementation research. Implement Sci. 2012;7(1):37.

22. A. Kruger R, Casey MA. Focus groups: a practical guide for applied research. 3rd ed. CA: Thousand Oaks CA: Sage Publications; 2000

23. StataCorp. Stata Statistical Software: Release 13. 2013. 2013.

24. Winkler EAH, Bodicoat DH, Healy GN, Bakrania K, Yates T, Owen N, et al. Identifying adults' valid waking wear time by automated estimation in activPAL data collected with a $24 \mathrm{~h}$ wear protocol. Physiol Meas IOP Publishing. 2016;37(10):1653-68.

25. Edwardson CL, Winkler EAH, Bodicoat DH, Yates T, Davies MJ, Dunstan DW et al. Considerations when using the activPAL monitor in field based research with adult populations. J Sport Heal Sci [Internet]. 2017;6(2):13-24 Available from: http://www.sciencedirect.com/science/article/pii/S2095254616000259.

26. Ritchie J, Lewis J, Nicholls CMN, Ormston R. Qualitative Research Practice: A Guide for Social Science Students and Researchers. Thousands Oaks: SAGE Publications; 2013.

27. QSR International Pty. NVivo qualitative data analysis Software, version 11. 2017

28. ONS. Census 2011. Census [Internet]. 2011;(May):78. Available from: http:// www.ons.gov.uk/ons/guide-method/census/2011/index.html. Accessed 30 Jan 2019.

29. Digital NHS England. Statistics on Obesity, Physical Activity and Diet [Internet]. 2017. Available from: https://digital.nhs.uk/data-and-information/ publications/statistical/statistics-on-obesity-physical-activity-and-diet/ statistics-on-obesity-physical-activity-and-diet-england-2017. Accessed 30 Jan 2019.

30. Simon SE. Sitting is the new smoking. Appl Radiol. 2015;44(10):6.

31. Baddeley B, Sornalingam S, Cooper M. Out of Hours Sitting is the new smoking: Where do we stand? Br J Gen Pract. 2016:258.

32. Pearson N, Haycraft $E_{1}$ Johnston JP, Atkin AJ. Sedentary behaviour across the primary-secondary school transition: a systematic review.
Prev med (Baltim). The Authors; 2017;94:40-47. Available from: https:// doi.org/10.1016/j.ypmed.2016.11.010

33. Cliff DP, Hesketh KD, Vella SA, Hinkley T, Tsiros MD, Ridgers ND, et al. Objectively measured sedentary behaviour and health and development in children and adolescents: systematic review and meta-analysis. Obes Rev. 2016;17(4):330-44.

34. Griffiths $\sqcup$, Sera F, Cortina-Borja M, Law C, Ness A, Dezateux C. Objectively measured physical activity and sedentary time: cross-sectional and prospective associations with adiposity in the Millennium Cohort Study. BMJ Open. 2016;6(4): e010366 Available from: http://www.pubmedcentral.nih.gov/articlerender. fcgi?artid=4838720\&tool=pmcentrez\&rendertype=abstract. Accessed 30 Jan 2019.

35. Jago R, Zahra J, Edwards MJ, Kesten JM, Solomon-Moore E, Thompson JL, et al. Managing the screen-viewing behaviours of children aged 5-6 years: a qualitative analysis of parental strategies. BMJ Open. 2016:e010355 Available from: https://bmjopen.bmj.com/content/bmjopen/6/3/e010355.full.pdf. Accessed 30 Jan 2019.

36. Veitch J, Hume C, Salmon J, Crawford D, Ball K. What helps children to be more active and less sedentary? Perceptions of mothers living in disadvantaged neighbourhoods. Child Care Health Dev. 2013;39(1):94-102.

37. Bentley GF, Jago R, Turner KM. Mothers' perceptions of the UK physical activity and sedentary behaviour guidelines for the early years (start active, stay active): a qualitative study. BMJ Open. 2015;5(9):e008383.

38. Quarmby T, Dagkas S, Bridge M. Associations between children's physical activities, sedentary behaviours and family structure: a sequential mixed methods approach. Health Educ Res. 2011;26(1):63-76.

39. Hornby-Turner YC, Hampshire KR, Pollard TM. A comparison of physical activity and sedentary behaviour in 9-11 year old British Pakistani and White British girls: A mixed methods study. Int J Behav Nutr Phys Act. 2014;11(1):74 Available from: http://www.pubmedcentral.nih.gov/articlerender.fcgi?artid= 4059029\&tool=pmcentrez\&rendertype=abstract. Accessed 30 Jan 2019.

40. R Hughes A, J Muggeridge D, Gibson A-M, Johnstone A, Kirk A. Objectively measured sedentary time in children and their parents. AIMS Public Heal. 2016;3(4):823-36.

41. Dowd KP, Harrington DM, Bourke AK, Nelson J, Donnelly AE. The measurement of sedentary patterns and behaviors using the activPAL ${ }^{\mathrm{TM}}$ professional physical activity monitor. Physiol Meas. 2012;33(11):1887-99.

42. Ridgers ND, Salmon J, Ridley K, O'Connell E, Arundell L, Timperio A. Agreement between activPAL and ActiGraph for assessing children's sedentary time. Int J Behav Nutr Phys Act. 2012;9:1-8.

43. Clarke-Moloney M, Godfrey A, O'Connor V, Meagher H, Burke PE, Kavanagh EG, et al. Mobility in patients with venous leg ulceration. Eur J Vasc Endovasc Surg. 2007;33(4):488-93.

44. Clemes SA, O'Connell SE, Edwardson CL. Office workers' objectively measured sedentary behavior and physical activity during and outside working hours. J Occup Environ Med United States. 2014;56(3):298-303.

45. Beck J, Chard CA, Hilzendegen C, Hill J, Stroebele-Benschop N. In-school versus out-of-school sedentary behavior patterns in U.S. children. BMC Obes; 2016;3(1):1-'. Available from: https://doi.org/10.1186/s40608-016-0115-3

46. Steele RM, van Sluijs EMF, Sharp SJ, Landsbaugh JR, Ekelund U, Griffin SJ. An investigation of patterns of children's sedentary and vigorous physical activity throughout the week. Int J Behav Nutr Phys Act. BioMed Central Ltd. 2010;7(1): 88 Available from: http://www.ijbnpa.org/content/7/1/88. Accessed 30 Jan 2019.

47. Sherry AP, Pearson N, Ridgers ND, Barber SE, Bingham DD, Nagy LC, et al. activPAL-measured sitting levels and patterns in 9-10 years old children from a UK city. J Public Health (Bangkok). 2018;fdy181-fdy181. Available from: https://doi.org/10.1093/pubmed/fdy181

48. Collings PJ, Brage S, Bingham DD, Costa S, West J, McEachan RRC, et al. Physical activity, sedentary time, and fatness in a Biethnic sample of young children. Med Sci Sports Exerc [Internet]. 2017;49(5):930-8 Available from: http://www. ncbi.nlm.nih.gov/pmc/articles/PMC5392414/. Accessed 30 Jan 2019.

49. Baker BC. Obesity statistics. House Commons Libr. 2017;3336.

50. World Health Organization. Physical activity for health More active people for a healthier world: draft global action plan. 2018;2014(December 2017):1-8.

51. Wilkie H, Standage M, Sherar L, Cumming S, Parnell C, Davis A, et al. Results From England 's 2016 Report Card on Physical Activity for Children and Youth. 2016;13(Suppl 2):143-9.

52. Chastin SFM, Craemer M De, Lien N, Bernaards C, Buck C, Oppert J, et al. The SOS-framework ( Systems of Sedentary behaviours ): an international transdisciplinary consensus framework for the study of determinants, research priorities and policy on sedentary behaviour across the life course: a. Int J Behav Nutr Phys Act. Int J Behav Nutr Phys Act; 2016;1-13. Available from: https://doi.org/10.1186/s12966-016-0409-3 